\title{
A REFORMA DO ESTADO E A MODERNIDADE ADMINISTRATIVA
}

A presença do Estado tem oscilado, no tempo e no espaço, segundo as variações da história política e econômica, impondo ao Direito Público transições conceituais e instrumentais, em correspondência ao movimento que procuramos definir como a variante do pêndulo entre pontos extremos na busca do equilíbrio (ver nosso ensaio sobre "O retorno do pêndulo: serviço público e empresa privada. O exemplo brasileiro - in Revista de Direito Administrativo - volume 202 - outubro-dezembro 1996 - p. 1/10).

Na evolução dos tempos, o desenvolvimento social e econômico caminha entre fases, que se sucedem, de maior ou menor amplitude da iniciativa privada em contraste com alternâncias de estatização.

A curva ascendente da ação executiva do Estado, iniciada na década de 30, marcou a expansão do intervencionismo e a multiplicação de entes paraestatais que, no entanto, cedeu passo, a partir da crise posterior à Segunda Guerra Mundial do século, a uma nova tendência nos caminhos da sociedade.

De uma parte, o fortalecimento dos direitos individuais se complementa com a garantia de direitos sociais e, mais recentemente, pela afirmação de direitos coletivos e difusos, em proteção da comunidade e da cidadania, conforme o modelo do direito comparado, abrigado, entre nós, na profusa coletânea de normas da Constituição de 1988.

A democratização política, fortalecendo o exercício de direitos oponíveis à ação unilateral do Estado, conduz a uma reavaliação dos poderes administrativos e a uma necessária descentralização de serviços públicos.

O Estado torna-se menor, retirando-se do domínio de áreas conquistadas pela iniciativa privada, embora subsistente a supervisão administrativa, em resguardo da finalidade pública. 
O Poder Público tende a concentrar-se na prestação de serviços públicos essenciais associados ao bem-estar, à educação, à cultura, à saúde e ao meio ambiente, limitando-se a exercer a vigilância e o complemento de atividades privadas segundo o princípio da subsidiariedade.

A política de privatização, que deita raízes, é a um tempo o modelo de retração do Estado na direta prestação de serviços de interesse geral como o fator determinante da reforma administrativa pela criação de novos entes reguladores da atividade transferida à execução de concessionários ou permissionários, ou antes de cooperação.

\section{II}

Estudando, em ensaio recente, os "Três momentos da privatização" (in Desafios do Século XXI - coletânea de estudos coordenada por Ives Gandra Martins - edição da Academia Internacional de Direito e Economia - 1997 - p. 140 e ss), destacamos o processo descentralizador, iniciado com o Programa Nacional de Desburocratização, objeto de Decreto $n^{0} 83.740$, de 18 de julho de 1979 , com a declarada finalidade de dinamizar e simplificar o funcionamento da Administração Pública Federal.

A política de descentralização tornou-se mais definida na década imediata, completando-se no Decreto no 95.886, de 29 de março de 1988, com o propósito de transferir à iniciativa privada determinadas atividades econômicas exploradas pelo Poder Público.

A Constituição de 1988 limita a atividade econômica do Estado segundo os imperativos da segurança nacional ou o relevante interesse coletivo definido em lei (art. 173) e convoca a iniciativa privada a retomar seu papel como fator dinâmico da economia.

Segundo dados oficiais, até 1989 , das empresas estatais incluídas no programa federal de desburocratização, 15 foram alienadas, 2 liquidadas, incorporadas outras e 14 transferidas ao plano estadual.

Com o advento da nova Constituição, nova etapa se formaliza na Medida Provisória no 155/90, logo convertida na Lei no 8.031, de 12 de abril do mesmo ano, que consolida o Programa Nacional de Desestatização.

Com adaptações de rumo e de procedimento espelhadas em sucessivas Medidas Provisórias, que inovam a Lei no $8.031 / 90$, a política de privatização marca, de forma significativa, a diretriz da moderna política governamental.

A Lei no 9.491, de 9 de dezembro de 1997, revoga e substitui a Lei no 8.031/90.

São igualmente reflexo da mesma política as Emendas Constitucionais $\mathrm{n}^{\circ} 6$, de 15 de agosto de 1995 , no 8, de 15 de agosto de 1995 e $n-9$, de 9 de novembro de 1995 que, limitando os monopólios de petróleo e de telecomunicações, abrem caminho à presença do capital estrangeiro e da iniciativa privada nacional, em medidas de privatização, objeto de sucessivas leis, conduzindo, por último, à Reforma Administrativa, expressa na Emenda Constitucional no 19, de 4 de junho de 1998. 
A Emenda Constitucional no $19 / 98$ atribui nova redação a oitenta preceitos da Carta Magna entre artigos, parágrafos, itens e alíneas e acrescenta sete novos artigos no sentido da adaptação do novo sistema, tendo como objetivos essenciais a maior eficiência no desempenho da atividade pública, bem como a valorização da produtividade dos servidores públicos e o estímulo à participação popular, visando à plenitude de resultados no funcionamento da máquina administrativa.

Mediante acréscimo no $\S 8^{\circ}$ ao art. 37 está prevista a ampliação da autonomia gerencial, orçamentária e financeira de órgãos e entidades da administração direta e indireta, a ser regulada em contrato que tenha por objeto a fixação de metas de desempenho.

Como instrumentos operacionais da política descentralizadora, são previstas, em lei, duas modalidades de agências administravas, a serem constituídas como autarquias especiais ou fundação.

Como processo interno de autonomia de determinados órgãos da estrutura da Administração Pública faculta-se a criação de Agências Executivas, mediante ato do Poder Executivo, nos termos do art. 51 da Lei no 9.649, de 27 de maio de 1998, oriundo da conversão da norma de igual teor, originariamente prevista como art. $48 \mathrm{da}$ Medida Provisória no $1.549 / 28$, de 14 de março de 1997, reeditada e sucedida pelas Medidas Provisórias no 1.642 e 1.651 .

Outro tipo de autarquias especiais, como efeito da privatização de serviços transferidos à iniciativa privada, são as Agências Reguladoras que operam com poderes de supervisão, fiscalização e normatização das empresas às quais foram delegados os serviços.

Paralelamente ao processo de descentralização administrativa, a lei permite, ainda, que, mediante contratos de gestão, entidades privadas possam ser habilitadas, em nome do Estado, como pessoas não estatais, a desempenhar atividades de caráter assistencial, atuando como entes de cooperação com o serviço público. São as denominadas organizações sociais, regidas pela Lei no 9.637, de 15 de maio de 1998.

\section{IV}

O novo modelo de agências inicia, entre nós, um esquema de independência e de modernidade administrativa, conforme textos legais recentes.

A aproximação, usualmente invocada, com o símile norte-americano e o de figuras equivalentes no plano do direito comparado, é antes terminológica do que real, em termos de substância.

O atual Plano Diretor da Reforma do Aparelho do Estado encontra, entre nós, como procedente histórico, a experiência de reforma empreendida pelo Departamento Administrativo do Serviço Público (DASP) que teve como instrumento o Decretolei $\mathrm{n}^{\mathrm{Q}} 200$, de 1967, complementado pelo Decreto-lei $\mathrm{n}^{\mathrm{Q}}$ 900, de 1969.

O figurino de então, compondo a administração pública indireta, distribuída entre autarquias, empresas públicas e sociedades de economia mista, cuidou de dinami- 
zar a produtividade do Estado, com a personalização dos entes paraestatais de operação flexível, segundo um planejamento coordenado.

Uma longa herança patrimonialista na gestão pública e a frequiência de abusos e desvios na condução das atividades descentralizadas levaram, contudo, a um processo crescente de limitação da autonomia a importar na inoperância de resultados.

A administração indireta, sob o imposto de medidas restritivas, nivelou-se, praticamente, com os métodos da administração direta no formalismo burocratizante de seus procedimentos.

A nova era que caracteriza o atual Governo caminha no sentido de objetivos de maior eficiência funcional cuidando-se de implantar, na definição do titular da respectiva pasta, "a reforma gerencial do Estado do brasileiro".

Estimula-se a descentralização do aparelho do Estado, com ênfase nos contratos de gestão e na maior cooperação entre a União, Estados e Municípios. Valoriza-se a participação dos usuários na Administração Pública e possibilita-se o acesso da autoridade a informações privilegiadas com o sentido de superar o isolamento burocrático e prover canais de circulação em benefício do interesse geral.

A criação das agências executivas é parte deste programa.

Não se resume, como no passado, apenas a personalizar entidades na administração indireta e a delegar-lhes competências específicas.

Predomina, na atual reforma, o sentido de prévio compromisso e a aferição de resultados como requisito de sobrevivência da agência executiva.

A Lei no 9.649, de 27 de maio de 1998 (fruto, como indicado, de sucessivas Medidas Provisórias) e a correspondente regulamentação marcam nitidamente o caráter finalístico das agências executivas e a continuidade do controle de sua real produtividade.

A criação como agência executiva tramita por uma sucessão de etapas, tendo como ponto de partida o ato de vontade da administração do órgão ou instituição que pretenda alcançar a qualificação.

Como pré-requisito deve a instituição oferecer ao Ministério a que estiver vinculada um plano estratégico que identifique as metas a serem cumpridas na busca da melhoria de qualidade na operação dos serviços.

Acolhida a proposta, será celebrado contrato de gestão visando a tornar efetiva a autonomia da instituição, como autarquia ou fundação e a determinar os indicadores que permitirão a periódica avaliação dos resultados.

Ao consenso por esta forma estabelecido sucederá, mediante decreto, a criação da agência executiva.

O cumprimento das metas de desempenho, nos prazos e condições estipulados, definirá a permanência do modelo, como prescreve o $\S 3^{\circ}$ do art. $1^{\circ}$ do Decreto $n^{\circ}$ 2.487, de 2 de fevereiro de 1998, in verbis: 
"Fica assegurada a manutenção da qualificação como Agência Executiva, desde que o contrato de gestão seja sucessivamente renovado e que o plano estratégico de reestruturação e de desenvolvimento institucional tenha prosseguimento ininterrupto, até a sua conclusão."

A não ser adequadamente cumprida a missão proposta, a desqualificação da Agência Executiva dar-se-á por iniciativa do Ministério supervisor, com anuência do Ministério da Administração Federal e Reforma do Estado (MARE), coordenador geral do sistema. Assim dispõe o $\S 4^{\circ}$ do art. $1^{\circ}$ do citado Decreto $\mathrm{n}^{\mathrm{o}} 2.487 / 98$.

É, em suma, pelo dinamismo operacional que se irá marcar o nascimento, vida e morte de uma Agência Executiva.

A primeira e concreta adoção do modelo se traduziu no Decreto de 29 de julho de 1998, qualificando como Agência Executiva o Instituto Nacional de Metrologia, Normatização e Qualidade Industrial (INMETRO), autarquia federal criada pela Lei no 5.966 , de 11 de dezembro de 1973.

\section{VI}

As Agências Executivas representam, como assinalado, um processo interno de desconcentração administrativa. Assumem, em nível de autonomia, a gestão de serviços públicos específicos que conservam a natureza estatal.

Diversamente, as Agências Reguladoras têm como pressuposto a privatização de serviços que, pela via de concessão ou permissão, são delegados à exploração privada.

Autarquias especiais, as Agências Reguladoras assumem as atribuições próprias do poder concedente, inclusive com poderes normativos. Caracterizam, por esta forma, a ação externa do poder público, regendo o regime dos serviços concedidos, em sua funcionalidade e no relacionamento com os usuários.

Três tipos de Agências Reguladoras ingressam no sistema, cada qual afeiçoado às peculiaridades do setor a que atendem.

Primeiramente, a Lei no 9.427, de 26 de dezembro de 1996, institui a Agência Nacional de Energia Elétrica (ANEEL) com a finalidade de regular e fiscalizar a produção, transmissão, distribuição e comercialização de energia elétrica, em conformidade com diretrizes do governo federal. Dirigida por um Diretor Geral e quatro diretores em regime colegiado, nomeados pelo Presidente da República, com mandatos de quatro anos, sucede ao Departamento Nacional de Águas e Energia Elétrica (DNAEE), com poderes amplos, regulamentados pelo Decreto $\mathrm{n}^{0} \mathbf{2} .335$, de 6 de outubro de 1997. Representando o poder concedente, tem atribuição de, celebrar e gerir contratos de concessão e de permissão no setor e de dirimir, no âmbito administrativo, divergências entre concessionários e entre estes e os consumidores.

Em modelo mais aperfeiçoado e adaptado às especificidades do respectivo mercado, aberto ao concurso da iniciativa privada, a Lei no 9.472, de 16 de julho de 1997 , regulamentada pelo Decreto no 2.338, de 7 de outubro de 1997, constitui a Agência Nacional de Telecomunicações (ANATEL), como órgão autárquico de administração dos correspondentes serviços. 
Tem como órgãos superiores o Conselho Diretor e o Conselho Consultivo. O primeiro, composto de cinco conselheiros, com mandatos de cinco anos, escolhidos pelo Presidente da República, com aprovação do Senado Federal, tem amplos poderes de gestão e de regulação dos diversos serviços de telecomunicações. O Conselho Consultivo é, na definição legal, o órgão de participação institucionalizada da sociedade, integrado por representantes indicados pelo Senado Federal, pela Câmara de Deputados, pelo Poder Executivo, pelas entidades de classe das prestadoras de serviços, por entidades representativas dos usuários e por entidades representativas da sociedade, nos termos do regulamento. É prevista a existência de Ouvidoria entre os órgãos da Agência. O Ouvidor, nomeado pelo Presidente da República, com mandato de dois anos, admitida uma recondução, tem por incumbência acompanhar a atuação da Agência e de seus servidores, encaminhando apreciações críticas aos órgãos superiores, ao Ministério das Comunicações, a outros órgãos do Poder Executivo e ao Congresso Nacional, e fazendo publicá-las para conhecimento geral.

Por força da Emenda Constitucional no 9, de 1995, que fez cessar o monopólio estatal no setor de petróleo, admitindo a participação da iniciativa privada, a Lei no 9.478, de 6 de agosto de 1997, institui a Agência Nacional de Petróleo (ANP) como órgão regulador da indústria respectiva. As atividades da Agência foram regulamentadas pelo Decreto no 2.455 , de 14 de janeiro de 1998.

Sem embargo da diversidade de cada área específica de atuação, as Agências Reguladoras apresentam, como características comuns, os seguintes pontos de afinidade:

a) constituídas como autarquias especiais, destacam-se da estrutura hierárquica dos Ministérios e da direta influência da conduta política do governo;

b) gozam de autonomia financeira, administrativa e especialmente de poderes normativos complementares à legislação;

c) dotados de poderes amplos de fiscalização, operam como instância administrativa final de litígios sobre matéria de sua competência;

d) respondem, fundamentalmente, pelo cumprimento de metas fixadas e pelo desempenho das atividades dos prestadores de serviço, segundo as diretrizes do Governo e em defesa do interesse da comunidade. ${ }^{1}$

\section{VII}

Figura correlata à política de participação privada em área de relevante interesse público merece ser referida como instrumento da modernidade administrativa.

A Lei no 9.637, de 15 de maio de 1998 (precedida das Medidas Provisórias no $1.591 / 97$ e 1.648/98), qualifica como Organizações Sociais entidades privadas, sem fim lucrativo, dirigidas ao ensino, à pesquisa científica, ao desenvolvimento tecnológico, à proteção e preservação do meio ambiente, à cultura e à saúde, que, mediante

1 A Lei no 9.782, de 26 de janeiro de 1999 criou a Agência Nacional de Vigilância Sanitária, como autarquia sob regime especial, vinculada ao Ministério da Saúde, com iguais características. 
contrato de gestão com órgão público supervisor, aplicarão recursos orçamentários e bens públicos na execução de suas atividades. Como entes de cooperação compõem formas de pessoas administrativas não estatais, limítrofes à administração pública indireta, pela finalidade pública que as distingue.

\section{VIII}

Os contratos de gestão, em suas diversas variantes, consagram-se como o instrumento formal por excelência dos programas de reforma administrativa, moldada na definição de metas de desempenho e na avaliação de resultados.

Tem merecido críticas a designação, como ato contratual, de uma figura de consenso que unifica interesses coincidentes, dirigidos no mesmo sentido de afirmação. Antes se identifica no pacto a ser celebrado a natureza de parceria ou acordo que associa partícipes de finalidades comuns.

Também mereceu reparos a inclusão, no texto da Emenda Constitucional $\mathrm{n}^{\mathbf{0}}$ 19/98, conforme o aditamento de novo parágrafo ao art. 37 da Constituição, da referência à administração direta como destinatária dos contratos a serem celebrados para a ampliação de autonomia.

A proposta original da emenda, oferecida pelo Poder Executive, circunscrevia o alcance da medida aos entes personalizados da administração indireta, aptos ao ato negocial.

O elemento histórico, segundo o depoimento de participantes, permite entender a motivação do paradoxo que importa na previsão, para a administração direta, em um contrato consigo mesma.

A reivindicação extensiva teria nascido de reivindicação da área militar que, embora desejosa de aplicar os efeitos da autonomia a hospitais e estaleiros militares, não desejava abdicar do princípio da hierarquia, inerente à tradição da categoria.

O ponto essencial do veículo associativo é, contudo, o caráter dinâmico, e não meramente formal, que tem como tônica a objetiva realização de uma estratégia operacional conducente à concretização de metas de desempenho e à consecução de resultados.

IX

O tempo dirá da eficácia e produtividade do ambicioso plano reformulador da Administração Pública e da política de cooperação que se procura inaugurar como mais outra das fórmulas do Direito Administrativo participativo, que é a marca moderna da harmonia entre o Estado e a sociedade, a que dedicamos recente ensaio ( $\mathrm{Re}$ vista de Direito Administrativo, vol. 209, p. 1/6). 


\section{Direitos Fundamentais Sociais: Estudos de Direito Constitucional, Internacional e Comparado}

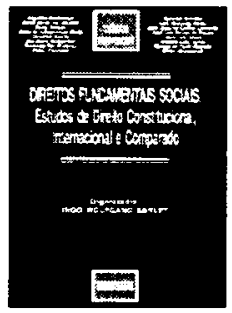

\author{
Ingo Wolfgang Sariet (org.) \\ Ref. 0472 \\ Brochura \\ 508 págs. \\ Form. $14 \times 21$ \\ 2003 \\ ISBN: $85-7147-322-6$
}

A obra versa sobre o tema que prescinde, em principio, de maior justificativa. Além disso, a sua acolhida pela doutrina majoritária tem revelado que, atualmente, são poucos os que recusam aos direitos sociais sua condição de direitos humanos fundamentais.

\section{Direitos Humanos na Sociedade Cosmopolita}

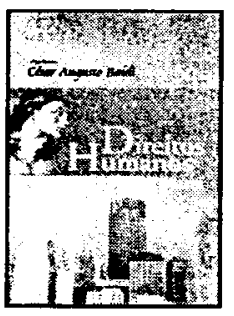

\section{César Augusto Baldi (org.)}

Ref. 512

Brochura

662 págs.

Form. $16 \times 23$

2004

ISBN 85-7147-445-1

Só uma política cosmopolita de direitos humanos é capaz de promover o diálogo intercultural entre a pretensão de universalidade dos direitos humanos ocidentais e, no outro pólo, as mais variadas tradições religiosas (budismo. hinduísmo, islamismo, confucionismo), as populações tradicionais e negras, movimentos teministas e LGBT, migrantes. Essa a proposta atualíssima e consistente da presente coletânea, a convergir para uma prática intensiva de direitos humanos, ancorada nas interfaces das diversas lutas por reconhecimento/redistribuição, igualdade/diferença e inclusāo/solidariedade.
Estado, Sociedade Civil e o Princípio da Subsidiariedade na Era da Globalização

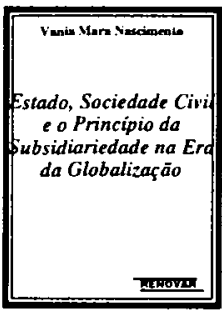

Vania Mara Nascimento

Ref. 0443

Brochura

220 págs.

Form. $13,5 \times 21$

2003

ISBN 85-7147-359-5

Abrange 5 capítulos. No $1^{\circ}$, apresenta-se, de forma descritiva, a Globalização, abordando sua origem, conceituação e características. № $2^{\circ}$, examina-se o papel e a crise do Estado e da Soberania frente à Globalização. No $3^{9}$ explana-se o Princípio da Subsidiariedade, sua origem, seu conceito, seu fundamento e sua aplicabilidade. № $4^{?}$, expōe-se o Estado Subsidiário, com a eclosão da Sociedade Civil participativa. No $5^{\circ}$, faz-se referência ao Principio da Subsidiarieade no Direito Comparado.

\section{Estudos Constitucionais Constituição Federal de 1988}

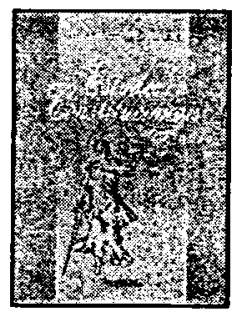

Aurea Pimentel Pereira

Ret. 0335

Brochura

440 págs.

Form. $14 \times 21$

2001

ISBN 85-7147-273-4

A autora faz uma sinopse crítica da Constituiçāo Federal de 1988, assinalando as impropriedades e antinomias cometidas pelo legislador constituinte quando de sua elaboração, e, ao depois, pelo poder constituinte derivado, por ocasião de emendas introduzidas a pretexto da realizaçāo de reformas sociais e administrativas - mas que. para a autora, vêm transformando a carta Política brasileira em verdadeira colcha de retalhos. 